\title{
Association of single nucleotide polymorphisms in FGF-RAS/MAP signalling cascade with breast cancer susceptibility
}

\author{
Zuzana Dankova ${ }^{1}$, Pavol Zubor ${ }^{1,2}$, Marian Grendar ${ }^{3}$, Andrea Kapinova ${ }^{1}$, Katarina Zelinova ${ }^{1,2}$, \\ Marianna Jagelkova ${ }^{1,2}$, Alexandra Gondova ${ }^{2}, K$ arol Dokus ${ }^{2}$, Michal Kalman $^{4}$, Zora Lasabova ${ }^{1}$ \\ and Jan Danko ${ }^{2}$ \\ ${ }^{1}$ Division of Oncology, Biomedical Center Martin, Jessenius Faculty of Medicine in Martin, Comenius University in Bratislava, \\ Martin, Slovakia \\ ${ }^{2}$ Department of Obstetrics and Gynecology, Jessenius Faculty of Medicine in Martin, Comenius University in Bratislava, Mar- \\ tin University Hospital, Martin, Slovakia \\ ${ }^{3}$ Bioinformatic unit, Biomedical Center Martin, Jessenius Faculty of Medicine in Martin, Comenius University in Bratislava, \\ Martin, Slovakia \\ ${ }^{4}$ Department of Pathology, Jessenius Faculty of Medicine in Martin, Comenius University in Bratislava, Martin University \\ Hospital, Martin, Slovakia
}

\begin{abstract}
The fibroblast growth factor receptors (FGFRs) and Ras/mitogen activated protein (RAS/ MAP) signalling cascades are the main molecular pathways involved in breast carcinogenesis. This study aims to determine the association between FGF10 (rs4415084 C>T), FGFR2 (rs2981582 C>T) and MAP3K1 (rs889312 A>C) gene polymorphisms and breast cancer, to analyse the discriminative ability of each SNP and to test the accuracy of the predictive breast cancer risk model which includes all SNPs. We conducted a case-control study of 170 women ( $57.06 \pm 11.60$ years) with histologically confirmed breast cancer and 146 controls (50.24 \pm 10.69 years). High resolution melting (HRM) method with Sanger sequencing validation was used in analyses. We have revealed significant association of FGFR2 and MAP3K1 polymorphisms with breast cancer. The odds ratio of FGFR2 T allele was 1.897 (95\% CI 1.231-2.936, $p=0.004)$ and MAP3K1 C allele 1.804 (95\% CI 1.151-2.845, $p=0.012$ ). FGFR2 polymorphism achieved the best discriminative ability $(41.95 \%)$. The Random Forest algorithm selected FGFR2, MAP3K1 and age as important breast cancer predictors. The accuracy of this prediction model approached moderate accuracy (70\%), with $35.9 \%$ sensitivity and $88.6 \%$ specificity.
\end{abstract}

Key words: ROC curve - HRM method - Carcinogenesis - Discriminative ability

\section{Introduction}

Breast cancer is a heterogeneous disease. On the molecular level, it develops and progresses from alterations in genes regulating biological processes such as cell growth, proliferation and differentiation (Harlid et al. 2012; Pham et al. 2013; Chen et al. 2016a; Toss et al. 2017). Large studies of genomic modifications and protein expression involved in breast tumorigenic pathways identified several differently penetrating

Correspondence to: Zuzana Danková, Division of Oncology, Biomedical Center Martin, Jessenius Faculty of Medicine in Martin, Comenius University in Bratislava, Martin, Slovakia E-mail: dankova@jfmed.uniba.sk polymorphisms associated with this disease and provided an increasing number of targets for drugs which significantly improve patient prognosis (Easton et al. 2007; Fachal and Dunning 2015; Michailidou et al. 2015). Emerging evidence from clinical trials has proven also that specific genetic background and molecular landscapes significantly influence the sensitivity and resistance profile (Wilson et al. 2016; Zardavas and Piccart-Gebhart 2016; Miller et al. 2017; Toss et al. 2017). Moreover, identification of molecular signatures and gene expression profiling is increasingly inevitable for full understanding of the tumorigenesis, especially in personalised targeted medicine (Ellsworth et al. 2010; Pereira et al. 2016).

Breast carcinogenesis is a complex of several mutually intertwined signalling pathways, such as 1) the oestrogen 
signalling pathway, 2) PI3K/AKT/mTOR pathway, 3) RAS/ MAPK signalling pathway, 4) angiogenic pathway and 5) the FGFR signalling or p53 pathway (Eroles et al. 2012; Pham et al. 2013; Suman et al. 2016). Genetic alterations at any level induce aberrant signalling, thus leading to increased cancer risk (Guille et al. 2013; Sullivan et al. 2016; $\mathrm{Ng}$ et al. 2017).

Fibroblast growth factor receptor 2 (FGFR2) is transmembrane tyrosine kinase receptor for FGF family members with high affinity for FGF10. Their binding induces functional FGFR dimerization and kinase activation by trans-autophoshorylation which activates multiple downstream cellular cascades and responses (Wesche et al. 2011; Tiong et al. 2013). The cascade involving mitogen-activated protein kinase 1 (MAP3K1), a serine-threonine kinase in the MAP3K family and the STE superfamily, comprises of several steps: activated FGFR kinase trigger stimulation of its intracellular substrates. Major FGFR substrate $2 \alpha$ (FRS2 $\alpha$ ) binds the adaptor protein growth factor receptor-bound 2 (GRB2) which recruits the guanine nucleotide exchange factor son of sevenless (SOS). It activates RAS GTPase which initiates activation of the whole RAS-RAF-MEK-MAPK cascade (Goetz and Mohammadi 2013). MAPK translocates from the cytoplasm to the nucleus, where it phosphorylates and triggers early gene transcription factors which mediate the expression of oncogenes involved in proliferation, cell differentiation, cell migration and survival (McCubrey et al. 2007; Jara et al. 2013; Pham et al. 2013; Zheng et al. 2014). The activation of this receptor tyrosine kinase signalling is thus one of the mechanisms underlying tumour development and growth and genetic alterations of genes involved in this cascade contribute to aberrant cell biology.

Diverse FGF10, FGFR2 and MAP3K1 gene polymorphisms have already been identified as breast cancer susceptible in various populations (Rebbeck et al. 2009; Ripperger 2009; Harlid et al. 2012; Jara et al. 2013; Murillo-Zamora et al. 2013; Pritchard and Hayward 2013; Siddiqui et al. 2014; Zheng et al. 2014; Campbell et al. 2016), and studies on breast cancer genetic background have also been performed in Slovakia (Franeková et al. 2007; Zubor et al. 2007, 2008, 2014; Kasajová et al. 2016). Results from these studies emphasised the relevance of several polymorphisms in breast cancer susceptibility and pointed out the importance of an inter-population genetic variability.

The aim of our case-control study was to determine the association of single-nucleotide polymorphisms in FGF10, FGFR2 and MAP3K1 genes with breast cancer in a sample of Slovak women. Furthermore, we focused on the discriminative ability of each SNP to determine the risk of disease status in individual patients and tested the accuracy of the disease prediction model including all SNPs by unconditional linear regression and the random forest classification algorithm.

\section{Materials and Methods}

\section{Subjects}

We conducted the case-control study with 170 women (57.06 \pm 11.60 years) with histopathologically diagnosed breast cancer and the control group comprised 146 healthy females (50.24 \pm 10.69 years) without previous history of breast carcinoma or other malignancies. Women were of Slavic Caucasian origin, and samples were collected at the Clinic of Gynaecology and Obstetrics at the Jessenius Faculty of Medicine in Martin, the Comenius University in Bratislava and University Hospital in Martin. All subjects gave written informed consent and study was approved by the Ethical Committee (EC 1269/2013) and implemented in accordance with the Declaration of Helsinki.

\section{Histopathological analyses}

Immunohistopathology parameters of breast cancer tissue samples were provided by the pathologists. Tumour and lymph node specimens were fixed in formalin and embedded in paraffin. The basic histological examination was performed on $4-5-\mu \mathrm{m}$-thick slides stained with haematoxylin and eosin. In selected cases, lymph nodes were stained immunohistochemically (cytokeratin 19) to detect potential isolated tumour cells or micrometastases. Tumour type and histological grade were evaluated according to the WHO criteria and Nottingham grading modification (Elston and Ellis 1991; Lakhani et al. 2012). Briefly, immunohistochemistry for oestrogen receptor (ER), progesterone receptor $(\mathrm{PR})$ and human epidermal growth factor receptor (HER2) was performed concurrently on serial sections with ready to use reagents using an automated immunostainer Autosteiner Link 48 (Dako; Agilent Technologies, Inc., Santa Clara, CA, USA). Primary ER antibody (FLEX Monoclonal Rabbit, ER alpha, clone EP1, RTU, IR08461) and PR antibody (FLEX Monoclonal Mouse, clone PgR636, RTU, IS0683) were supplied by Dako; Agilent Technologies, Inc. (Santa Clara, CA, USA). Antigen retrieval was performed using EnVision ${ }^{T M}$ FLEX Target Retrieval Solution High $\mathrm{pH}$ ( $\mathrm{pH} 9.0$ ) for $20 \mathrm{~min}$ at $97-98^{\circ} \mathrm{C}$ in PT Link instrument (Dako; Agilent Technologies, Inc., Santa Clara, CA, USA). Endogenous peroxidase activity was blocked by $10 \mathrm{~min}$ incubation in $3 \%$ hydrogen peroxide, followed by antibody incubation for $20 \mathrm{~min}$ at room temperature. EnVision ${ }^{\mathrm{TM}}$ FLEX/HRP, High pH kit (K8000, Dako; Agilent Technologies, Inc., Santa Clara, CA, USA) was used as detection system according to the manufacturer's instructions. The immunohistochemistry for HER2 was performed using a HercepTest ${ }^{\mathrm{TM}}$ Breast+Gastric kit (SK001, Dako; Agilent Technologies, Inc., Santa Clara, CA, USA). Antigens were retrieved in HercepTest ${ }^{\text {TM }}$ Epitop Retrieval Solution $(\mathrm{pH}$ 
6.0), using PT Link for $40 \mathrm{~min}$ at $97-98^{\circ} \mathrm{C}$. Sections were blocked for endogenous peroxidase in $3 \%$ hydrogen peroxide for $10 \mathrm{~min}$, then incubated with primary antibody for $30 \mathrm{~min}$ at room temperature. HercepTest ${ }^{\mathrm{TM}}$ Visualization Reagents were used $30 \mathrm{~min}$ at room temperature according to the manufacturer's instructions.

ER, PR and HER2 status were interpreted following the American Society of Clinical Oncology/College of American Pathologists criteria from 2010 and 2013 (Hammond et al. 2010; Wolff et al. 2013). Tumours were considered as ER and $\mathrm{PR}$ positive if $\geq 1 \%$ of neoplastic cells stained positively. Positive HER2 status was considered for cases exhibiting a $3+$ reaction in $\geq 10 \%$ of neoplastic cells. Cases with $2+$ reaction of HER2 staining were considered as equivocal and were analysed by fluorescent in situ hybridization to confirm or exclude HER2 gene amplification. Table 1 provides information on histological type, grade, receptor status and molecular subtypes of the studies samples.

\section{DNA extraction and HRM assays}

DNA was isolated from the peripheral blood using the commercially available isolation kit based on silica gel membranes, and sample concentrations were analysed by Qubit fluorometer. All samples were diluted in sterile distilled water to $20 \mathrm{ng} / \mu \mathrm{l}$ final concentration.

Genotyping was performed by high resolution melting (HRM) method which is based on the different disassociation characteristics of double-stranded DNA amplicons and fluorescence measurement. Validated positive controls of all genotypes and negative controls were included in each analysis which ran in a 96-well plate in the LightCycler ${ }^{\circledR} 480$ Real-Time PCR System (Roche Diagnostics). The singletube mixture was prepared in a total volume of $20 \mu \mathrm{l}$ (Light Cycler Master Mix $10.0 \mu \mathrm{l}, 25 \mathrm{mM} \mathrm{MgCl}_{2} 2.4 \mu \mathrm{l}, 10 \mathrm{pmol}$ P1 $0.4 \mu \mathrm{l}, 10$ mol P2 $0.4 \mu \mathrm{l}, \mathrm{H}_{2} \mathrm{O} 4.8 \mu \mathrm{l}, 20$ ng DNA $2.0 \mu \mathrm{l}$ ). We designed all primers in accordance with HRM method requirements and using Primer3 online application. The
Table 1. Histopathological characteristics of breast cancer patients

\begin{tabular}{lc}
\hline & Frequency (\%) \\
\hline Histological type & 76.0 \\
DIC & 7.8 \\
LIC & 1.9 \\
DCIS & 14.3 \\
Other & \\
\hline Histological grade & 16.7 \\
Grade 1 & 38.3 \\
Grade 2 & 45.0 \\
Grade 3 & \\
\hline ER status & 85.8 \\
ER-positive & 14.2 \\
ER-negative & \\
\hline PR status & 79.8 \\
PR-positive & 20.2 \\
PR-negative & 16.5 \\
\hline HER2 status & 83.5 \\
PR-positive & \\
PR-negative & 79.8 \\
\hline Molecular subtype & 13.8 \\
Luminal A & 3.7 \\
Luminal B & 2.8 \\
TN BC & \\
HER2 & \\
\hline DIC duca invarive & \\
\hline
\end{tabular}

DIC, ducal invasive cancer; LIC, lobular invasive cancer; DCIS, ductal cancer in situ; ER, oestrogen receptor; PR, progesterone receptor; HER2, human epidermal growth factor receptor 2.

specificity was checked by Primer-BLAST application and formation of dimers by OligoAnalyzer tool 3.1. Primer sequences were as follows: rs4415084 (FGF10): forward 5'-TAGCCCTGTTGTATTCCTGATGAC-3' and reverse 5' -AAGATTGCTGTATGTGTGGCAGGT-3'; rs2981582 (FGFR2) forward 5'-CGAGAATAAAACGGCAGATCCC-3', reverse 5'-GACTGCTGCGGGTTCCTAAAG-3'

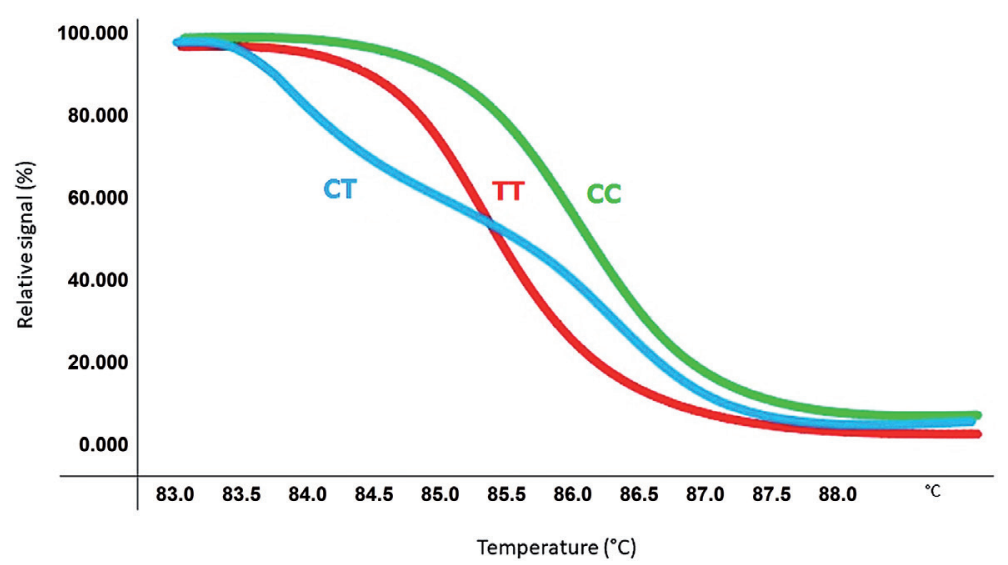

Figure 1. Schematic HRM (high resolution melting) curves determining CT, TT and CC FGFR2 genotypes. Different melting curves represent three genotypes. The curve course and temperature of the melting depends on the amplicon sequence. At the beginning of the HRM analysis the fluorescence is high as the dye is bound to dsDNA amplicons. By heating, dsDNA decreases as the DNA is melting and the fluorescence is reduced. 
Table 2. Genotype and allele frequencies of polymorphisms in FGF10, FGFR2 and MAP3K1 genes

\begin{tabular}{|c|c|c|c|c|c|c|}
\hline \multirow[b]{2}{*}{$F G F 10 \mathrm{C}>\mathrm{T}$} & \multirow[b]{2}{*}{$\mathrm{CC}$} & \multicolumn{2}{|l|}{$\begin{array}{c}\text { Genotype } \\
n(\%)\end{array}$} & \multicolumn{2}{|c|}{ Allele } & \\
\hline & & $\mathrm{CT}$ & TT & $C$ & $T$ & \\
\hline Cases (170) & $49(28.7)$ & $77(45.0)$ & $45(26.3)$ & 0.51 & 0.49 & $\chi^{2}=1.895 p=0.388$ \\
\hline Controls (146) & $52(35.6)$ & $57(39.0)$ & $37(25.3)$ & 0.55 & 0.45 & \\
\hline FGFR2 C $>\mathrm{T}$ & $\mathrm{CC}$ & $\mathrm{CT}$ & TT & $C$ & $T$ & \\
\hline Cases (170) & $57(33.5)$ & $81(47.6)$ & $32(18.9)$ & 0.57 & 0.43 & $\chi^{2}=6.879 p=0.032^{\star}$ \\
\hline Controls (146) & $70(47.9)$ & $56(38.4)$ & $20(13.7)$ & 0.67 & 0.33 & \\
\hline$M A P 3 K 1 \mathrm{~A}>\mathrm{C}$ & AA & $\mathrm{AC}$ & $\mathrm{CC}$ & $A$ & $C$ & \\
\hline Cases (170) & $79(46.2)$ & $79(46.2)$ & $13(7.6)$ & 0.69 & 0.31 & $\chi^{2}=8.383 p=0.015^{*}$ \\
\hline Controls (146) & $90(61.6)$ & $51(34.9)$ & $5(3.4)$ & 0.79 & 0.21 & \\
\hline
\end{tabular}

Frequencies of genotypes are shown as number $(n)$ and percent $(\%) ;{ }^{*} p<0.05$.

and rs889312 (MAP3K1) forward 5' - ACACAAGTCAGGCCCCATTA-3', reverse 5'-TGGGAAGGAGTCGTTGAGTT-3'. The genotypes were determined by the different shapes of the melting curve (Figure 1). Several samples from each SNP were validated by Sanger sequencing. The PCR samples were purificated by Nucleo Spin Gel and PCR Cleanup kit and by SigmaSpin ${ }^{\text {TM }}$ Sequencing Reaction Clean-Up. The analyses were carried out on the 3500 Genetic Analyzer (Applied Biosystems $^{\mathrm{TM}}$ ). The sequences were read with free trace viewer Chromas program v.2.6.2.

\section{Statistical analyses}

The conformity of genotypes distribution with HardyWeinberg Equilibrium was tested by a goodness-of-fit $\chi^{2}$ test in both controls and cases groups. The comparison of genotype distribution between cases and controls was tested by the $\chi^{2}$ test with Monte-Carlo $p$-values. Odds ratios and their $95 \%$ confidence intervals were obtained in logistic regression, with adjustment for age. The predictive accuracy of the model was measured by the area under the ROC

Table 3. Odds ratios of the FGF10, FGFR2 and MAP3K1 genotypes

\begin{tabular}{|c|c|c|c|c|}
\hline & \multirow{2}{*}{ OR } & \multicolumn{2}{|c|}{$95 \% \mathrm{CI}$} & \multirow{2}{*}{$p$} \\
\hline & & Lower bound & Upper bound & \\
\hline \multicolumn{5}{|c|}{$F G F 10 C>T$} \\
\hline CT & 1.43 & 0.85 & 2.42 & 0.188 \\
\hline TT & 1.29 & 0.72 & 2.32 & 0.458 \\
\hline \multicolumn{5}{|c|}{ FGFR2 $C>T$} \\
\hline CT & 1.77 & 1.09 & 2.89 & $0.026^{*}$ \\
\hline TT & 1.95 & 1.01 & 3.83 & $0.049^{\star}$ \\
\hline \multicolumn{5}{|c|}{$M A P 3 K 1 A>C$} \\
\hline $\mathrm{AC}$ & 1.76 & 1.11 & 2.81 & $0.019^{\star}$ \\
\hline $\mathrm{CC}$ & 2.89 & 1.03 & 9.57 & $0.048^{\star}$ \\
\hline
\end{tabular}

OR, odds ratio; CI, confidence interval; ${ }^{\star} p<0.05$. (receiver operating characteristic) curve. The random forest classification algorithm with the nested cross-validation feature selection was used to obtain a realistic estimate of the predictive performance of the breast cancer risk model.

All data were analysed using $\mathrm{R}$ software (R Core Team, 2015) and IBM SPSS program version 21. $p$ values below 0.05 were considered statistically significant.

\section{Results}

The distribution of genotypes and allele frequencies of all three SNPs according to health status are shown in Table 2. Genotypes with risk minor alleles occurred more often in all three SNPs in the breast cancer case group than in the control group. However, statistical analyses revealed significant association only between the FGFR2 $(p=0.032)$ and MAP3K1 $(p=0.015)$ gene polymorphisms and breast cancer susceptibility. The genotype distribution of all SNPs showed conformity with Hardy-Weinberg Equilibrium criteria in both study groups $(p>0.05)$ except for FGF10 genotype distribution in the control group $(p=0.011)$.

Table 3 shows the odds ratios of heterozygotes and homozygotes with two minor risk alleles of the three studied polymorphisms. Individuals with two minor alleles in homozygous form had higher risk than heterozygotes in FGFR2 (OR 1.95 vs. 1.77) and in MAP3K1 (OR 2.89 vs. 1.76) polymorphisms. The range of confidence intervals and $p$-values for rs4415084 FGF10 polymorphism confirmed that neither homozygosity nor heterozygosity for the $T$ variant is associated with increased breast cancer risk.

We also analysed association of these polymorphisms with histopathological characteristics of the samples displayed in the Table 1. However, neither the association of three polymorphisms and tumour type, histological grade, receptor status nor molecular subtype was statistically significant $(p<0.05)$. 
To assess the predictive capability of single SNPs, we calculated classification error of each SNP. Although the best value was found for FGFR2 polymorphism (41.95\%), its discriminative ability was low (Table 4).

ROC curves and the area under the ROC curve (AUC) were used to quantify the predictive accuracy of the multivariate logistic regression model of all studied SNPs. FGFR2, MAP3K1 polymorphisms and age were statistically significant predictors of breast cancer in the model. The accuracy of this prediction model approached $70 \%$, with moderate accuracy (Figure 2).

The Random Forest algorithm was applied to the data as an alternate predictive algorithm in order to obtain a realistic estimate of the predictive performance of the three SNPs and age by nested cross-validation feature selection. This algorithm also determined FGFR2, MAP3K1 and age as the important breast cancer predictors. The predictive accuracy of this model was $67.3 \%$ with $35.9 \%$ sensitivity and $88.6 \%$ specificity.

\section{Discussion}

Our study confirmed significant associations of lowpenetrant FGFR2 and MAP3K1 polymorphisms with breast cancer risk in Slovak women. However, we found no evidence to implicate the FGF10 $T$ allele polymorphism as a breast cancer risk factor even though this had been previously identified by large-scale and genome-wide association breast cancer studies (Easton et al. 2007; Hunter et al. 2007; Stacey et al. 2008). The odds ratios for FGFR2 heterozygous and homozygous form (1.77 and 1.95) and for MAP3K1 (1.76 and 2.89) were higher than reported in the literature (1.2 and 1.6 for FGFR2 and 1.1 and 1.3 for MAP3K1) (Easton et al. 2007; Ripperger et al. 2009). These differences can be explained by inter-population variability but also by sample size.

Although, the MAP3K1 mutations were more frequently observed in HER2+ breast cancer and FGFR2 variants are reported relevant in ER+ and $\mathrm{PR}+$ breast cancer (Pham et al. 2013; Campbell et al. 2016), we found no significant association between genetic polymorphisms and histopathological characteristics of the cancer samples. Further

Table 4. Discriminative ability of three SNPs according to the classification error

\begin{tabular}{lcc}
\hline & $\begin{array}{c}\text { Classification } \\
\text { error (\%) }\end{array}$ & $\begin{array}{c}\text { Discriminative } \\
\text { ability }\end{array}$ \\
\hline$F G F 10 C>T$ & 45.11 & low \\
$F G F R 2 C>T$ & 41.95 & low \\
$M A P 3 K 1 A>C$ & 42.59 & low \\
\hline
\end{tabular}

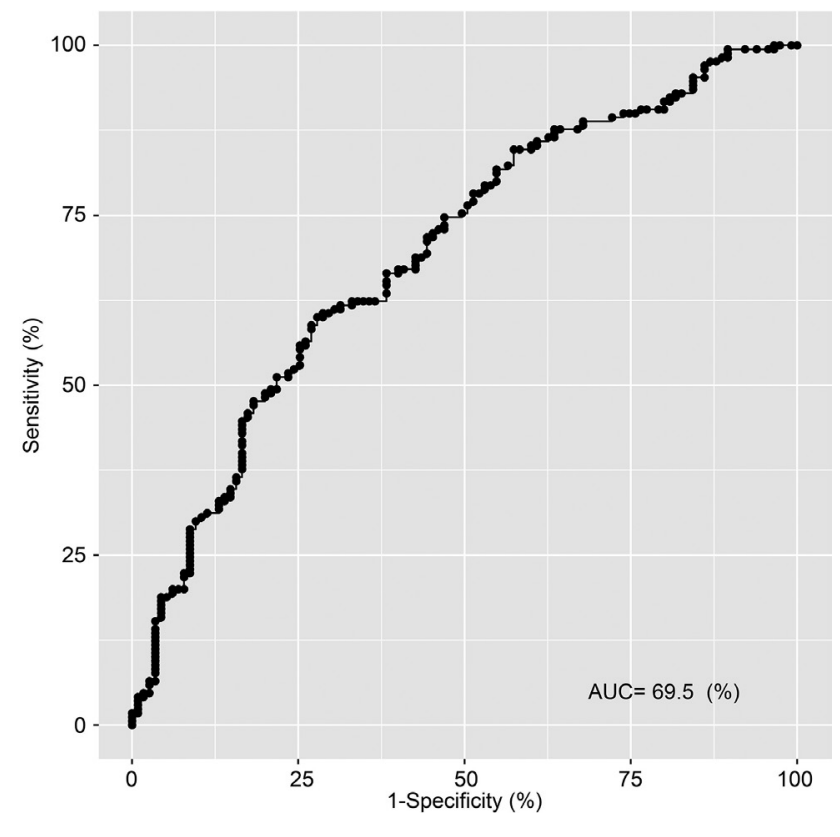

Figure 2. ROC (receiver operating characteristic) curve with the area under the ROC curve (AUC) for the multivariate logistic regression model. The position of the ROC on the graph reflects the accuracy of the diagnostic test. Closer to the upper left corner, the better, as the area under the curve is higher, which means better prediction power of the model based on higher sensitivity and specificity.

studies of other polymorphisms in these genes and the expression profile could elicit essential information because FGFR2 is a tumour suppressor gene amplified and overexpressed in $10-15 \%$ of breast tumours (Rebbeck et al. 2009; Ahmad et al. 2012; Tiong et al. 2013) and enhanced FGFR expression may not only be due to genetic alterations but also to epigenetic deregulation at transcriptional and post-translational levels.

Multiple studies have already examined and confirmed the association of these low-penetrant genes with breast cancer susceptibility in several populations (Easton et al. 2007; Rebbeck et al. 2009; Murillo-Zamora et al. 2013; Chen et al. 2016b). However, most of these did not assess SNP's predictive capability, and this is one of the most important factors for precision medicine (Wu et al. 2016). To understand the discriminative ability of studied SNPs, individually, we computed the classification error. Our results indicate that overall accuracy was weak using classification error; ranging from $41.95 \%$ to $45.11 \%$. With regard to low-penetrating SNPs, it is assumed that more SNPs have greater cumulative power, and therefore, we generated ROC curve of the multivariate logistic regression model which includes all three studied genotypes. Based on the AUC value of 0.695 , the model's predictive performance approached moderate accuracy. 
Wu et al. (2016) analysed more SNPs and the AUCs for the models with 10, 22 and 77 SNPs were 0.591, 0.622 and 0.684, respectively, and this indicates that more SNPs the prediction model includes, the better discriminative ability the model attains. However, their last model with 153 SNPs demonstrated lower predictive performance in terms of AUC 0.650. It appears that the common genetic variants attained the upper limit of their predictive power. Higher AUC value of our model might be explained by age, one of the main determinants in breast carcinogenesis, which we included in our model. Further, because the logistic regression overfits data and provides upward-biased estimates of accuracy, sensitivity and specificity, we employed the Random Forest algorithm with nested cross-validation selection to obtain a realistic estimate of the SNP's predictive ability with age. This provided us with lower, but realistic estimate of model's accuracy (67.3\%). We assume that inclusion of other clinical risk factors could increase the predictive power of the models.

In conclusion, we confirmed FGFR2 and MAP $3 K 1$ as breast cancer susceptible genes with $T$ allele (FGFR2 rs2981582) and $C$ allele (MAP3K1 rs889312) elevating the disease risk. The discriminative ability of single SNP models was low. Based on the AUC value of 0.695 , the model's predictive performance approached moderate accuracy.

Further studies examining more low-penetrant genes and combination of highly-, moderate- and low-penetrant polymorphisms involved in another main signalling pathways, together with clinical characteristics would enhance assessment of the cumulative role of genetic variants in breast carcinogenesis and determine their diagnostic accuracy.

Acknowledgement. This work was supported by the Slovak Research and Development Agency grant under the contract No. APVV-14-0815 and by KEGA grant No. 015UK-4/2015 and by VEGA 1/0199/17 and VEGA 1/0124/17.

Conflict of interest. There is no conflict of interest, and no competing financial interests exist.

\section{References}

Ahmad I., Iwata T., Leung H. Y. (2012): Mechanisms of FGFR-mediated carcinogenesis. Biochim. Biophys. Acta 1823, 850-860 https://doi.org/10.1016/j.bbamcr.2012.01.004

Campbell T. M., Castro M. A., de Santiago I., Fletcher M. N., Halim S., Prathalingam R., Ponder B. A., Meyer K. B. (2016): FGFR2 risk SNPs confer breast cancer risk by augmenting oestrogen responsiveness. Carcinogenesis 37, 741-750 https://doi.org/10.1093/carcin/bgw065

Chen F., Gao S., Wang F., Ma J., Zhang M., Lv M., Zhou Q., Fu Z., Lu Ch., Yin H. (2016a): Comprehensive profiling of biological processes reveals two major prognostic subtypes in breast cancer. Tumour Biol. 37, 3365-3370 https://doi.org/10.1007/s13277-015-4173-9

Chen Y., Shi Ch., Guo Q. (2016b): TNRC9 rs12443621 and FGFR2 rs2981582 polymorphisms and breast cancer risk. World J. Surg. Oncol. 14, 50 https://doi.org/10.1186/s12957-016-0795-7

Easton D. F., Pooley K. A., Dunning A. M., Pharoah P. D., Thompson D., Ballinger D. G., Struewing J. P., Morrison J., Field H., Luben R. et al. (2007): Genome-wide association study identifies novel breast cancer susceptibility loci. Nature 447, 1087-1093 https://doi.org/10.1038/nature05887

Ellsworth R. E., Decewicz D. J., Shriver C. D., Ellsworth D. L. (2010): Breast cancer in the personal genomics era. Curr. Genomics 11, 146-161 https://doi.org/10.2174/138920210791110951

Elston C. W., Ellis I. O. (1991): Pathological prognostic factors in breast cancer. I. The value of histological grade in breast cancer: experience from a large study with long-term follow-up. Histopatology 19, 403-410 https://doi.org/10.1111/j.1365-2559.1991.tb00229.x

Eroles P., Bosch A., Pérez-Fidalgo J. A., Lluch A. (2012): Molecular biology in breast cancer: Intrinsic subtypes and signaling pathways. Cancer Treat. Rev. 38, 698-707 https://doi.org/10.1016/j.ctrv.2011.11.005

Fachal L., Dunning A. M. (2015): From candidate gene studies to GWAS and post-GWAS analyses in breast cancer. Curr. Opin. Genet. Dev. 30, 32-41 https://doi.org/10.1016/j.gde.2015.01.004

Franeková M., Zúbor P., Stanclová A., Dussan C. A., Bohusová T., Galo S., Dobrota D., Kajo K., Péc M., Racay P. (2007): Association of p53 polymorphisms with breast cancer: a case-control study in Slovak population. Neoplasma 54, 155-161

Guille A., Chaffanet M., Birnbaum D. (2013): Signalling pathway switch in breast cancer. Cancer Cell Int. 13, 66 https://doi.org/10.1186/1475-2867-13-66

Goetz R., Mohammadi M. (2013): Exploring mechanisms of FGF signalling through the lens of structural biology. Nat. Rev. Mol. Cell Biol. 14, 166-180 https://doi.org/10.1038/nrm3528

Hammond M. E. H., Haves D. F., Wolff A. C., Mangu P. B., Temin S. (2010): American Society of Clinical Oncology/College of American Pathologists guideline recommendations for immunohistochemical testing of estrogen and progesterone receptors in breast cancer. Arch. Pathol. Lab. Med. 134, E1-E16

Harlid S., Ivarsson M. I., Butt S., Grzybowska E., Eyfjörd J. E., Lenner P., Försti A., Hemminki K., Manjer J., Dillner J., Carlson J. (2012): Combined effect of low-penetrant SNPs on breast cancer risk. Br. J. Cancer 106, 389-396 https://doi.org/10.1038/bjc.2011.461

Hunter D. J., Kraft P., Jacobs K. B., Cox D. G., Yeager M., Hankinson S. E., Wacholder S., Wang Z., Welch R., Hutchinson A., et al. (2007): A genome-wide association study identifies alleles in FGFR2 associated with risk of sporadic postmenopausal breast cancer. Nat. Genet. 39, 870-874 https://doi.org/10.1038/ng2075

Jara L., Gonzalez-Hormazabal P., Cerce-o K., Di Capua G. A., Reyes J. M., Blanco R., Bravo T., Peralta O., Gomez F., Waugh E. et al. (2013): Genetic variants in FGFR2 and MAP3K1 are associated with the risk of familial and early-onset breast 
cancer in a South-American population. Breast Cancer Res. Treat. 137, 559-569 https://doi.org/10.1007/s10549-012-2359-z

Kasajova P, Holubekova V, Mendelova A, Lasabova Z, Zubor P, Kudela E, Biskupska-Bodova K, Danko J. (2016): Active cigarette smoking and the risk of breast cancer at the level of $\mathrm{N}$-acetyltransferase 2 (NAT2) gene polymorphisms. Tumour Biol. 37, 7929-7937 https://doi.org/10.1007/s13277-015-4685-3

Lakhani S. R., Ellis I. O., Schnitt S. J., Tan P. H., van de Vijver M. J. (2012): WHO Classification of Tumours of the Breast. 4th ed., Lyon, IARC

McCubrey J. A., Steelman L. S., Chappell W. H., Abrams S. L., Wong E. W., Chang F., Lehmann B., Terrian D. M., Milella M., Tafuri A. et al. (2007): Roles of the Raf/MEK/ERK pathway in cell growth, malignant transformation and drug resistance. Biochim. Biophys. Acta 1773, 1263-1284 https://doi.org/10.1016/j.bbamcr.2006.10.001

Michailidou K., Beesley J., Lindstrom S., Canisius S., Dennis J., Lush M. J., Maranian M. J., Bolla M. K., Wang Q., Shah M. et al. (2015): Genome-wide association analysis of more than $\mathbf{1 2 0 , 0 0 0 ~ i n d i v i d u a l s ~ i d e n t i f i e s ~} 15$ new susceptibility loci for breast cancer. Nat. Genet. 47, 373-380 https://doi.org/10.1038/ng.3242

Miller J. A., Kotecha R., Ahluwalia M. S., Mohammadi A. M., Chao S. T., Barnett G. H., Murphy E. S., Vogelbaum M. A., Angelov L., Peereboom D. M., Suh J. H. (2017): Overall survival and the response to radiotherapy among molecular subtypes of breast cancer brain metastases treated with targeted therapies. Cancer 123, 2283-2293 https://doi.org/10.1002/cncr.30616

Murillo-Zamora E., Moreno-Macías H., Ziv E., Romieu I., LazcanoPonce E., Angeles-Llerenas A., Pérez-Rodríguez E., Vidal-Millán S., Fejerman L., Torres-Mejía G. (2013): Association between rs2981582 polymorphism in the FGFR2 gene and the risk of breast cancer in Mexican women. Arch. Med. Res. 44, 459-466 https://doi.org/10.1016/j.arcmed.2013.08.006

Ng Ch. K. Y., Piscuoglio S., Geyer F. C., Burke K. A., Pareja F., Eberle C., Lim R., Natrajan R, Riaz N., Mariani O. et al. (2017): The landscape of somatic genetic alterations in metaplastic breast carcinomas. Clin. Cancer Res. 7, 11479 https://doi.org/10.1158/1078-0432.CCR-16-2857

Pereira B., Chin S. F., Rueda O. M., Vollan H. K., Provenzano E., Bardwell H. A., Pugh M., Jones L., Russell R., Sammut S. J. et al. (2016): The somatic mutation profiles of 2,433 breast cancers refine their genomic and transcriptomic landscapes. Nat. Commun. 7, 11479 https://doi.org/10.1038/ncomms11479

Pham T. T., Angus S. P., Johnson G. L. (2013): MAP3K1. Genomic alterations in cancer and function in promoting cell survival or apoptosis. Genes Cancer 4, 419-426 https://doi.org/10.1177/1947601913513950

Pritchard A. L., Hayward N. K. (2013): Molecular pathways: mitogen-activated protein kinase pathway mutations and drug resistance. Clin. Cancer Res. 19, 2301-2309 https://doi.org/10.1158/1078-0432.CCR-12-0383

Siddiqui S., Chattopadhyay S., Akhtar S., Najm M. Z., Deo S. V. S., Shukla N. K., Syed A. Husain A. (2014): A study on genetic variants of fibroblast growth factor receptor 2 (FGFR2) and the risk of breast cancer from north India. PLoS One 9, e110426

https://doi.org/10.1371/journal.pone.0110426

Stacey D., Samant R., Bennett C. (2008): Decision making in oncology: a review of patient decision aids to support patient participation. CA Cancer J. Clin. 58, 293-304 https://doi.org/10.3322/CA.2008.0006

Sullivan L. B., Gui D. Y., Vander Heiden M. G. (2016): Altered metabolite levels in cancer: implications for tumour biology and cancer therapy. Nat. Rev. Cancer 16, 680-693 https://doi.org/10.1038/nrc.2016.85

Ripperger T., Gadzicki D., Meindl A., Schlegelberger B. (2009): Breast cancer susceptibility: current knowledge and implications for genetic counselling. Eur. J. Hum. Genet. 17, $722-731$ https://doi.org/10.1038/ejhg.2008.212

Rebbeck T. R., DeMichele A., Tran T. V., Panossian S., Bunin G. R., Troxel A. B., Strom B. L. (2009): Hormone-dependent effects of FGFR2 and MAP3K1 in breast cancer susceptibility in a population-based sample of post-menopausal AfricanAmerican and European-American women. Carcinogenesis 30, 269-274 https://doi.org/10.1093/carcin/bgn247

Suman S., Sharma P. K., Rai G., Mishra S., Arora D., Gupta P., Shukla Y. (2016): Current perspectives of molecular pathways involved in chronic inflammation-mediated breast cancer. Biochem. Biophys. Res. Commun. 472, 401-409 https://doi.org/10.1016/j.bbrc.2015.10.133

Tiong K. H., Mah L. Y., Leong Ch. O. (2013): Functional roles of fibroblast growth factor receptors (FGFRs) signaling in human cancers. Apoptosis 18, 1447-1468 https://doi.org/10.1007/s10495-013-0886-7

Toss A., Venturelli M., Peterle Ch., Piacentini F., Cascinu S., Cortesi L. (2017): Molecular biomarkers for prediction of targeted therapy response in metastatic breast cancer: trick or treat? Int. J. Mol. Sci. 18, 85 https://doi.org/10.3390/ijms18010085

Wesche J., Haglund K., Haugsten E. M. (2011): Fibroblast growth factors and their receptors in cancer. Biochem. J. 437, 199-213 https://doi.org/10.1042/BJ20101603

Wilson T. R., Yu J., Lu X., Spoerke J. M., Xiao Y., O'Brien C., Savage H. M., Huw L-Y., Zou W., Koeppen H. et al. (2016): The molecular landscape of high-risk early breast cancer: comprehensive biomarker analysis of a phase III adjuvant population. NPJ Breast Cancer 2, 16022 https://doi.org/10.1038/npjbcancer.2016.22

Wolff A. C., Hammond M. E., Hicks D. G., Dowsett M., McShane L. M., Allison K. H., Allred D. C., Bartlett J. M., Bilous M., Fitzgibbons P. et al. (2013): American Society of Clinical Oncology; College of American Pathologists. Recommendations for human epidermal growth factor receptor 2 testing in breast cancer: American Society of Clinical Oncology/College of American Pathologists clinical practice guideline update. J. Clin. Oncol. 31, 3997-4013 https://doi.org/10.1200/JCO.2013.50.9984

Wu Y., Abbey C. K., Liu J., Ong I., Peissig P., Onitilo A. A., Fan J., Yuan M., Burnside E. S. (2016): Discriminatory power of com- 
mon genetic variants in personalized breast cancer diagnosis. Proc. SPIE Int. Soc. Opt. Eng. 9787, 978706

Zardavas D., Piccart-Gebhart M. (2016): New generation of breast cancer clinical trials implementing molecular profiling. Cancer Biol. Med. 13, 226-235 https://doi.org/10.20892/j.issn.2095-3941.2015.0099

Zheng Q., Ye J., Wu H., Yu Q., Cao J. (2014): Association between mitogen-activated protein kinase kinase kinase 1 polymorphisms and breast cancer susceptibility: a meta-analysis of 20 case-control studies. PLoS One 9, e90771 https://doi.org/10.1371/journal.pone.0090771

Zubor P., Lasabova Z., Hatok J., Stanclova A., Danko J. (2007): A polymorphism C3435T of the MDR-1 gene associated with smoking or high body mass index increases the risk of sporadic breast cancer in women. Oncol. Rep. 18, 211-217 https://doi.org/10.3892/or.18.1.211

Zubor P., Kajo K., Stanclova A., Szunyogh N., Galo S., Dussan C. A., Minarik G., Visnovsky J., Danko J. (2008): Human epithelial growth factor receptor 2[Ile655Val] polymorphism and risk of breast fibroadenoma. Eur. J. Cancer Prev. 17, 33-38 https://doi.org/10.1097/CEJ.0b013e3280145e4b

Zubor P., Caliskan M., Kajo K., Soybir G., Topuzlu C., Danko J. (2014): Ethnic disparities in breast cancer between Central Europe Caucasian women of Slavic origin and Middle East Turkish subjects. Neoplasma 61, 110-117 https://doi.org/10.4149/neo_2014_015

Received: March 31, 2017

Final version accepted: July 27, 2017 